\title{
Тонкие пленки СеВ6, полученные методом электронно-лучевого напыления на различных подложках
}

\author{
() А.А. Кузанян ${ }^{1}$, А.С. Кузанян ${ }^{1}$, Г.Р. Бадалян ${ }^{1}$, С.И. Петросян ${ }^{1}$, В.О. Варданян ${ }^{1}$, \\ В.Н. Гурин ${ }^{2}$, М.П. Волков ${ }^{2}$, С.Х. Пилосян ${ }^{3}$ \\ ${ }^{1}$ Институт фризических исследований Национальной академии наук Армении, \\ 0203 Аштарак, Армения \\ ${ }^{2}$ Физико-технический институт им. А.Ф. Иоффре Российской академии наук, \\ 194021 Санкт Петербург, Россия \\ ${ }^{3}$ Физический институт им. П.Н. Лебедева Российской академии наук, \\ 119991 Москва, Россия \\ E-mail: astghik.kuzanyan@gmail.com
}

(Получена 31 января 2017 г. Принята к печати 8 февраля 2017 г.)

\begin{abstract}
Методом электронно-лучевого напыления получены пленки гексаборида церия - материала, перспективного для использования в термоэлектрических устройствах при гелиевых температурах. Напыление проводили с керамических мишеней на диэлектрические, полупроводниковые и металлические подложки при различных температурах. Подробно исследованы микроструктура, элементный и фазовый составы, температурные зависимости удельного сопротивления и коэффициента Зеебека. Получены пленки со структурой $\mathrm{CaB}_{6}$, характерной для гексаборида церия, и элементным составом, близким к стехиометрическому. При низких температурах пленки имеют удельное сопротивление несколько больше, а коэффициент Зеебека близок к значениям для монокристаллических образцов. Основной причиной различия величин удельного сопротивления является обнаруженная в пленках большая концентрация примеси кислорода.
\end{abstract}

DOI: 10.21883/FTP.2017.08.44783.52

\section{1. Введение}

Перспективными термоэлектрическими материалами для использования при гелиевых температурах являются гексаборид церия $\mathrm{CeB}_{6}$ и гексаборид лантана с небольшим содержанием церия $\left(\mathrm{La}_{0.99} \mathrm{Ce}_{0.01}\right) \mathrm{B}_{6}[1,2]$. Максимальное значение термоэлектрической добротности $\left(\mathrm{La}_{0.99} \mathrm{Ce}_{0.01}\right) \mathrm{B}_{6} Z T=0.1$ и достигается при $\sim 0.3 \mathrm{~K}$. Более высокие значения $Z T=0.25$ получены для монокристаллов $\mathrm{CeB}_{6}$ при $9 \mathrm{~K}$ [3]. Низкие температуры необходимы для уменьшения шумов при работе однофотонных термоэлектрических детекторов [4], чувствительным элементом которых являются тонкие пленки. В литературе мало публикаций, посвященных получению и исследованию пленок $\mathrm{CeB}_{6}$ [5-7], при этом недостаточно исследовано влияние различных подложек на структуру и свойства пленок. В настоящей работе приведены результаты исследования пленок $\mathrm{CeB}_{6}$, полученных методом электронно-лучевого напыления на различных подложках. Были изучены микроструктура, элементный и фазовый состав пленок, температурная зависимость удельного сопротивления и коэффициента Зеебека.

\section{2. Получение тонких пленок $\mathrm{CeB}_{6}$ и методика эксперимента}

Пленки напыляли с использованием керамических мишеней методом электронно-лучевого напыления на диэлектрические $\left(\mathrm{Al}_{2} \mathrm{O}_{3}, \mathrm{AlN}\right)$, полупроводниковые $(\mathrm{Si})$ и металлические $(\mathrm{Mo}, \mathrm{W})$ подложки. Использование металлических подложек связано с тем, что в проектируемых тонкопленочных болометрах планируется использовать в качестве поглотителя фотонов тонкие пленки вольфрама на поверхности пленок $\mathrm{CeB}_{6}$. В держателе одновременно располагались 12 подложек размерами $10 \times 10$ мм на расстоянии $18 \mathrm{~cm}$ от мишени. Напыление проводилось при давлении 0.0025 Па и токе эмиссии 80-100 мА. Морфологию поверхности исследовали с помощью электронного микроскопа „VEGA TS5130MМ“, элементный состав — рентгеновского микроанализатора „INCA Energy 300“. Концентрацию церия, бора и кислорода определяли с погрешностью \pm 0.3 , 1.5 и 0.2 ат\% соответственно. Удельное сопротивление (четырехзондовым методом) и коэффициент Зеебека (методом прямого измерения напряжения при определенном градиенте температур вдоль пленки) измеряли в области температур $3.8-300 \mathrm{~K}$.

\section{3. Экспериментальные результаты и обсуждение}

Полученные пленки имели структуру $\mathrm{CaB}_{6}$, характерную для гексаборида церия. На рентгеновских дифрактограммах пленок присутствовал только пик (100). Преимущественная ориентация пленок имела место независимо от материала подложки и температуры напыления. В таблице приведены основные параметры напыления и данные рентгеновского микроанализа пленок: номер напыления, маркировка пленки, температура напыления $T_{d}$, продолжительность напыления $t_{d}$, толщина пленки $d$ и средняя скорость напыления $V$, которая определялась как отношение толщины к продолжительности 
Параметры напыления и данные рентгеновского микроанализа

\begin{tabular}{|c|c|c|c|c|c|c|c|}
\hline \multirow{2}{*}{$\begin{array}{c}\text { № } \\
\text { напыления }\end{array}$} & \multirow{2}{*}{$\begin{array}{c}\text { Маркировка } \\
\text { пленки }\end{array}$} & \multirow{2}{*}{$T_{d},{ }^{\circ} \mathrm{C}$} & \multirow{2}{*}{$t_{d}, \mathrm{c}$} & \multirow{2}{*}{$d, \mathrm{HM}$} & \multirow{2}{*}{$V, \mathrm{HM} / \mathrm{c}$} & \multicolumn{2}{|c|}{ Состав } \\
\hline & & & & & & $\mathrm{B} / \mathrm{Ce}$ & $\mathrm{O}, \mathrm{aT} \%$ \\
\hline 1 & $1-2 \mathrm{c} / \mathrm{Si}$ & $800-820$ & 900 & 287 & 19 & 5.23 & 9.17 \\
\hline 2 & $2-2 \mathrm{c} / \mathrm{Si}$ & $900-930$ & 900 & 390 & 26 & 3.9 & 4.12 \\
\hline 3 & $3-2 \mathrm{c} / \mathrm{Si}$ & $800-820$ & 900 & 251 & 17 & 6.2 & 3.58 \\
\hline 4 & $\begin{array}{l}4-2 \mathrm{c} / \mathrm{Si} \\
4-1 \mathrm{~d} / \mathrm{Mo}\end{array}$ & $900-910$ & 900 & 301 & 20 & $\begin{array}{l}5.42 \\
6.47\end{array}$ & $\begin{array}{l}7.75 \\
7.02\end{array}$ \\
\hline 5 & $\begin{array}{l}5-2 \mathrm{c} / \mathrm{Si} \\
5-1 \mathrm{~d} / \mathrm{Mo} \\
5-2 \mathrm{a} / \mathrm{W}\end{array}$ & $800-810$ & 900 & 529 & 35 & $\begin{array}{l}5.48 \\
6.02 \\
6.03\end{array}$ & $\begin{array}{l}6.45 \\
7.88 \\
7.81\end{array}$ \\
\hline 6 & $\begin{array}{l}\text { 6-2c/Si } \\
6-1 \mathrm{~d} / \mathrm{Mo} \\
6-2 \mathrm{a} / \mathrm{W}\end{array}$ & 900 & 900 & 167 & 11 & $\begin{array}{l}4.32 \\
6.48 \\
5.27\end{array}$ & $\begin{array}{r}14.16 \\
1.82 \\
12.49\end{array}$ \\
\hline 7 & $\begin{array}{l}7-2 \mathrm{c} / \mathrm{Si} \\
7-1 \mathrm{~d} / \mathrm{Mo} \\
7-2 \mathrm{a} / \mathrm{W}\end{array}$ & $700-710$ & 900 & 486 & 32 & $\begin{array}{c}5.4 \\
5.14 \\
5.55\end{array}$ & $\begin{array}{l}4.56 \\
4.65 \\
6.92\end{array}$ \\
\hline 8 & $\begin{array}{l}8-2 \mathrm{c} / \mathrm{Si} \\
8-1 \mathrm{~d} / \mathrm{Mo} \\
8-2 \mathrm{a} / \mathrm{W}\end{array}$ & 710 & 180 & 325 & 108 & $\begin{array}{l}4.72 \\
4.61 \\
4.72\end{array}$ & $\begin{array}{l}4.27 \\
4.38 \\
5.45\end{array}$ \\
\hline 9 & $\begin{array}{l}9-2 \mathrm{c} / \mathrm{Si} \\
9-1 \mathrm{~d} / \mathrm{Mo} \\
9-2 \mathrm{a} / \mathrm{W}\end{array}$ & $750-760$ & 900 & 524 & 35 & $\begin{array}{l}5.36 \\
5.93 \\
5.48\end{array}$ & $\begin{array}{l}4.32 \\
5.81 \\
5.61\end{array}$ \\
\hline 10 & $\begin{array}{l}10-2 \mathrm{c} / \mathrm{Si} \\
10-1 \mathrm{~d} / \mathrm{Mo} \\
10-2 \mathrm{a} / \mathrm{W}\end{array}$ & 900 & 1500 & 399 & 16 & $\begin{array}{l}4.97 \\
6.18 \\
5.55\end{array}$ & $\begin{array}{l}2.69 \\
4.24 \\
4.6\end{array}$ \\
\hline
\end{tabular}

напыления. В таблице также приведены данные элементного состава пленок: отношение концентраций в ат\% основных элементов $(\mathrm{B} / \mathrm{Ce})$ и содержание кислорода.

Поверхности пленок были зеркально гладкими. Исключением являются пленки на $\mathrm{Si}$ подложках, изменение морфологии поверхности которых при $T_{d}>900^{\circ} \mathrm{C}$ обусловлено образованием столбчатой структуры. Исследование элементного состава свидетельствует о присутствии кислорода во всех пленках. Очевидно, что обеспечиваемый в напылительной установке вакуум недостаточен. Соотношение основных элементов $(\mathrm{B} / \mathrm{Ce})$ меняется в широких пределах. У пленок, которые напыляли при одинаковых условиях в одном процессе напыления, соотношение В/Се может отличаться незначительно (напыления № $5,8,9$ ) или существенно (напыления № 6,10). Близким к стехиометрическому значению соотношением $\mathrm{B} / \mathrm{Ce}=6$ обладают пленки $1 \mathrm{~d} / \mathrm{Mo}$ и $2 \mathrm{a} / \mathrm{W}$ напыления № 5 , однако они содержат довольно много кислорода. Содержание кислорода меньше в пленках 1d/Мо напылений № 9, 10. Можно ожидать, что именно эти пленки будут обладать наиболее высокими термоэлектрическими характеристиками. В данной работе мы ограничились исследованием термоэлектрических характеристик пленок на подложках $\mathrm{Al}_{2} \mathrm{O}_{3}, \mathrm{AlN}$ и $\mathrm{Si}$. На рис. 1 представлена температурная зави- симость удельного сопротивления пленок напылений № 3-8. Характер полученных зависимостей совпадает с литературными данными для монокристаллических образцов, а именно наблюдается максимум удельного сопротивления при $5 \mathrm{~K}$ и минимум при $100-150 \mathrm{~K}$.

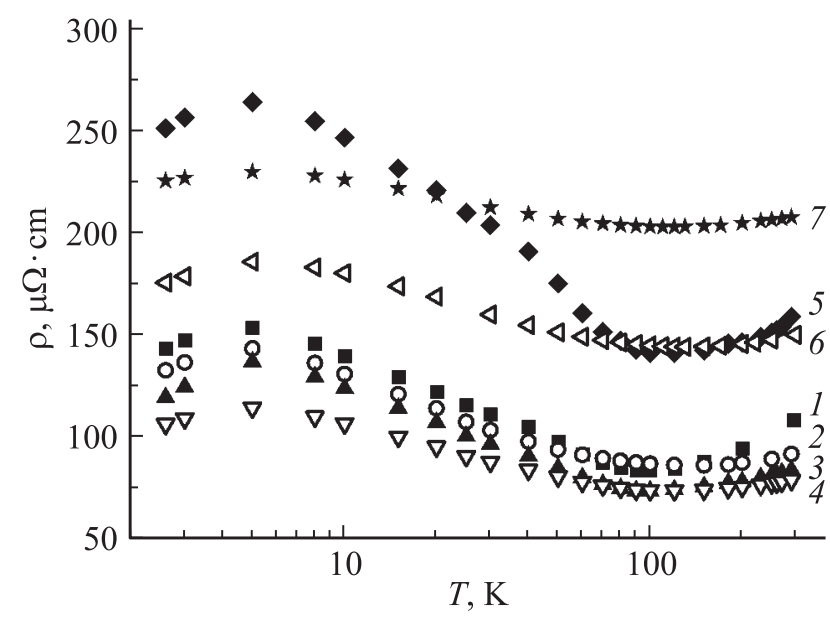

Рис. 1. Температурная зависимость удельного сопротивления пленок $\mathrm{CeB}_{6}: 1-3-2 \mathrm{c} / \mathrm{Si}, 2-4-1 \mathrm{~b} / \mathrm{AlN}, 3-4-2 \mathrm{c} / \mathrm{Si}$, $4-5-2 \mathrm{c} / \mathrm{Si}, 5-6-2 \mathrm{c} / \mathrm{Si}, 6-7-2 \mathrm{~b} / \mathrm{Al}_{2} \mathrm{O}_{3}, 7-8-2 \mathrm{c} / \mathrm{Si}$. 


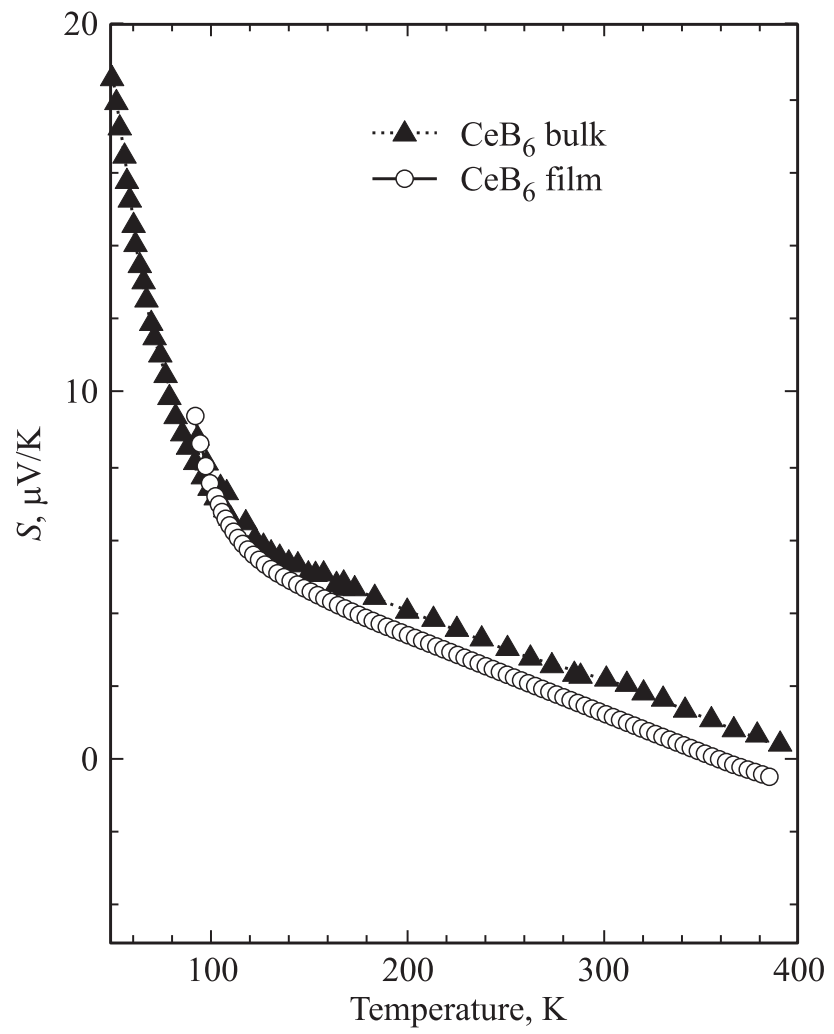

Рис. 2. Температурная зависимость коэффициента Зеебека пленок $\mathrm{CeB}_{6}$ на подложках $\mathrm{Al}_{2} \mathrm{O}_{3}$.

У монокристаллов сопротивление в области $5-300 \mathrm{~K}$ изменяется в пределах 30-75 мкОм · см. Для пленочных образцов оно несколько больше, причем сопротивление пленок с содержанием кислорода $>5$ ат\% увеличивается с увеличением концентрации кислорода. На рис. 2 приведены результаты измерений температурной зависимости коэффициента Зеебека образцов на подложках $\mathrm{Al}_{2} \mathrm{O}_{3}$. Ход зависимости $S(T)$ пленок напоминает результаты измерения монокристаллических образцов [2], однако абсолютные значения немного меньше при температурах $300-150 \mathrm{~K}$ и практически совпадают в области $150-77 \mathrm{~K}$.

\section{4. Заключение}

Исследованы микроструктура поверхности, фазовый и элементный состав, а также температурные зависимости сопротивления и коэффициента Зеебека пленок гексаборида церия, полученных методом электроннолучевого напыления при различных условиях на различных подложках. Удельное сопротивление пленок несколько больше, чем у монокристаллических образцов. Возможным решением задачи получения пленок с улучшенными характеристиками может быть использование мишеней из полиэлементных гексаборидов редкоземельных металлов [8], в которых вероятно более полное заполнение структурных вакансий.
Исследование выполнено при финансовой поддержке ГКН МОН Республики Армения и РФФИ в рамках совместных научных программ 15RF-018 и 15-53-05047 соответственно. Авторы благодарят А.Т. Буркова за помощь в измерениях термоэдс и обсуждении результатов.

\section{Список литературы}

[1] G.G. Fritz, K.S. Wood, D. Van Vechten, A.L. Gyulamiryan, A.S. Kuzanyan, N.J. Giordano, T.M. Jacobs, H.-D. Wu, J.S. Horwits, A.M. Gulian. Proc. SPIE, 4140, 459 (2000).

[2] В.А. Петросян. Изв. НАН Армении. Физика, 46, 194 (2011).

[3] S. Harutyunyan, V. Vardanyan, A. Kuzanyan, V. Nikoghosyan, S. Kunii, A. Gulian. Appl. Phys. Lett., 83 (11), 2142 (2003).

[4] A. Kuzanian, V. Nikoghosyan, A. Kuzanyan. Sensors \& Transducers, 191 (8), 57 (2015).

[5] J.Q. Xu, T. Mori, Y. Bando, D. Golberg, D. Berthebaud, A. Prytuliak. Mater. Sci. Engin. B, 177, 117 (2012).

[6] D. Hatanaka, E. Asanuma, K. Takeda, T. Ikeda, M. Nakamura, Y. Nakanishi, F. Iga, Y. Harada, H. Yamaguchi, M. Yoshizawa. Proc. Int. Conf. Strongly Correlated Electron Systems (SCES2013), JPS Conf. Proc., 011049 (2014).

[7] H. Shishido, K. Kawai, A. Futagami, S. Noguchi, T. Ishida JPS Conf. Proc, 011045 (2014).

[8] К.М. Макеев, В.Н. Гурин, Л.И. Деркаченко, М.П. Волков, А.С. Кузанян, А.А. Кузанян, Т.Б. Попова, Е.В. Иванова. Письма ЖТФ, 42 (1), 3 (2016).

Редактор А.Н. Смирнов

\section{Thin films of $\mathrm{CeB}_{6}$ obtained by electron beam deposition on different substrates}

\author{
A.A. Kuzanyan ${ }^{1}$, A.S. Kuzanyan ${ }^{1}$, G.R. Badalyan ${ }^{1}$, \\ S.I. Petrosyan 1, V.O. Vardanyan ${ }^{1}$, V.N. Gurin ${ }^{2}$, \\ M.P. Volkov ${ }^{2}$, S.Kh. Pilosyan ${ }^{3}$ \\ ${ }^{1}$ Institute for Physical Research, \\ National Academy of Sciences of Armenia, \\ 0203 Ashtarak, Armenia \\ 2 Ioffe Institute, Russian Academy of Sciences, \\ 194021 St. Petersburg, Russia \\ ${ }^{3}$ P.N. Lebedev Physical Institute \\ of the Russian Academy of Sciences, \\ 119991 Moscow, Russia
}

Abstract Cerium hexaboride films which are promising for use in thermoelectric devices at liquid-helium temperatures have been obtained by electron beam deposition method. Sputtering was carried out at various temperatures using ceramic targets and dielectric, semiconductor or metallic substrates. The microstructure, elemental and phase composition, the temperature dependence of the resistivity and Seebeck coefficient were investigated in details. Films possessing the $\mathrm{CaB}_{6}$ structure typical for cerium hexaboride and with elemental composition close to the stoichiometric formula were obtained. At low temperatures the films however exhibit a higher resistivity however a similar Seebeck coefficient, as compared to those in single crystal samples. The main reason for the observed difference is attributed to the large concentration of oxygen impurities detected in the films. 